\title{
Bacteriophage Protects Against Aerococcus viridans Infection in a Murine Mastitis Model
}

\begin{abstract}
Hengyu $\mathrm{Xi}^{1+}$, Dali He ${ }^{1 \dagger}$, Dong $\mathrm{Li}^{2+}$, Shan-shan $\mathrm{Liu}^{3}$, Gang Wang ${ }^{1}$, Yalu $\mathrm{Ji}^{1}$, Xinwu Wang ${ }^{1}$, Zijing Wang ${ }^{1}$, Lanting $\mathrm{Bi}^{1}$, Rihong Zhao ${ }^{1}$, Hao Zhang ${ }^{1}$, Li Yang ${ }^{1}$, Zhimin Guo ${ }^{4}$, Wenyu Han ${ }^{1,5}$ and Jingmin $\mathrm{Gu}^{1 *}$

${ }^{1}$ Key Laboratory of Zoonosis Research, Ministry of Education, College of Veterinary Medicine, Jilin University, Changchun, China, ${ }^{2}$ Department of Immunology, College of Basic Medical Sciences, Jilin University, Changchun, China, ${ }^{3}$ Department of Chinese Journal of Veterinary Science, Jilin University, Changchun, China, ${ }^{4}$ Department of Clinical Laboratory, The First Hospital of Jilin University, Changchun, China, ${ }^{5}$ Jiangsu Co-Innovation Center for the Prevention and Control of Important Animal Infectious Disease and Zoonose, Yangzhou University, Yangzhou, China
\end{abstract}

Bovine mastitis, an inflammatory disease that occurs frequently in early lactation or the dry period, is primarily caused by bacterial infections. There is growing evidence that Aerococcus viridans (A. viridans) is becoming an important cause of bovine mastitis. The treatment of bovine mastitis is primarily based on antibiotics, which not only leads to a large economic burden but also the development of antibiotic resistance. On the other hand, bacteriophages present a promising alternative treatment strategy. The object of this study was to evaluate the potential of a previously isolated $A$. viridans phage vB_AviM_AVP (AVP) as an anti-mastitis agent in an experimental A. viridans-induced murine mastitis model. A. viridans N14 was isolated from the milk of clinical bovine mastitis and used to establish a mastitis model in mice. We demonstrated that administration of phage AVP significantly reduced colony formation by $A$. viridans and alleviated damage to breast tissue. In addition, reduced inflammation was indicated by decreased levels of inflammatory cytokines (TNF- $\alpha$, IL-1 $\beta$, and IL-6) and myeloperoxidase (MPO) activity in the phage-treated group compared to those in the phosphate buffered saline (PBS)-treated group. To the best of our knowledge, this report is the first to show the potential use of phages as a treatment for $A$. viridans-induced mastitis.

Keywords: bacteriophage, Aerococcus viridans, bovine mastitis, murine model, phage therapy

\section{INTRODUCTION}

Bovine mastitis is an inflammatory response primarily caused by infection of the udder tissue, which has a serious impact on the health of dairy cows and the quality of their milk (1). Bovine mastitis results in prevalent and large-scale financial losses in the global dairy industry (2). With advances in the modern dairy industry, farmers have been constantly seeking low-cost and effective ways to minimize the damage caused by mastitis. Although optimizing the milking process, antibiotic use and disposal of infected animals decreased this damage, these methods led to an increase in the cost of milk production. Even more worrying is the emergence of drug resistance and the contamination of residues in milk due to the overuse of antibiotics $(2,3)$. As a result, restrictions on antibiotics and new methods for combating resistant bacteria are urgently needed globally (3-5), making the development of new drugs and the discovery of new treatments even more important. 
Mastitis is considered to be primarily caused by major pathogens, such as Streptococcus agalactiae, Streptococcus uberis and Staphylococcus aureus, while infections by these pathogens have decreased in recent decades due to the implementation of specific control strategies $(6,7)$. The incidence of mastitis caused by minor pathogens, including Corynebacterium spp. and coagulase-negative staphylococci, is increasing $(8,9)$. In this case, $A$. viridans bacteria are increasingly becoming a common pathogen causing mastitis $(10,11)$. A viridans is a Gram-positive opportunistic pathogen that belongs to the family Aerococcaceae and is widely distributed in the environment, that is, air, water, and soil (12). In 2004, Zadoks et al. detected A. viridans in $50 \%$ of bulk milk samples from 48 dairy farms in the USA (13). The isolation rates of A. viridans in subclinical mastitis in China reported by Liu et al. (14) and Sun et al. (10) were 6.1 and $16.67 \%$, respectively. In addition, in a 2015 report in Japan, the incidence of $A$. viridans was $8 \%$ in 478 cases of clinical mastitis, while the incidences of Streptococcus spp. and coagulasenegative Staphylococcus were 9.2 and $3.1 \%$, respectively (15). In recent studies, Liu et al. confirmed that virulent $A$. viridans had the ability to adhere and invade bMECs and possessed strong cytotoxicity (16). However, the mechanism by which $A$. viridans causes mastitis has not been elucidated. More disturbingly, antibiotic-resistant strains of $A$. viridans are also increasing $(14,17)$.

Bacteriophage therapy may represent a promising alternative to antibiotics due to its ability to specifically infect and kill bacteria. The treatment of humans by bacteriophages has been achieved in Poland, Georgia and Russia and has a long history (18). According to the data published by the Phage Therapy Center of the Hirszfeld Institute of Immunology and Experimental Therapy in Wroclaw, 35-50\% of patients received positive feedback after phage treatment (19). In addition, bacteriophages also have useful application in veterinary clinics (20). Researchers have reported that phages can be used for the treatment of infections caused by multiple drug-resistant bacteria, such as Enterococcus faecium (21), Escherichia coli (22), and Pseudomonas aeruginosa (23). In previous studies, phages were effective in treating $S$. aureus and E. coli-induced mastitis models in mice $(24,25)$. These results indicate that phage therapy is feasible, but there is no report describing the use of phage therapy in the treatment of mastitis caused by $A$. viridans to date.

In our previous study, the first phage of $A$. viridans was isolated, and its general biological characteristics and genomic characteristics were analyzed (26), indicating that it is safe at the genome level and has potential for application. In this study, the murine mastitis model was established by $A$. viridans, and the therapeutic effect of phage vB_AviM_AVP (AVP) on the murine mastitis model was evaluated.

\section{MATERIALS AND METHODS}

\section{Ethics Statement}

All animal studies were conducted according to the National Guidelines for Experimental Animal Welfare (Ministry of Science and Technology of China, 2006) and were approved by the Animal Welfare and Research Ethics Committee at
Jilin University (Permit Number: pzpx20181227051). In the experiment, the animals were treated humanely, and every effort was made to reduce the suffering of the animals.

\section{Bacterial Strains and Culture Conditions}

Bacterial strains M13-1, N14, N15, M6-1, M19-1, and $\mathrm{P}_{1-1} \mathrm{~F}_{2}$ were all isolated from milk samples of dairy cows with clinical mastitis. Milk samples were cultured overnight on blood agar plates, and circular colonies with off-white color that could form $\alpha$-hemolysis were selected from the mixture containing various bacteria. Next, the suspected colonies were subjected to pure culture and a series of identifications to confirm whether they were A. viridans. The initial identification was based on the colony morphology, hemolytic reaction, and microscopic morphology followed by PCR with a pair of specific primers $\mathrm{F}$ (5'-GTGCTTGCACTTCTGACGTTAGC$3^{\prime}$ ) and R (5'-TGAGCCGTGGGCTTTCACAT-3') (27). The PCR amplification products were sequenced and aligned using Nucleotide-Blast in the NCBI database. CZ4b-3 and Aer-1 Aer-6 were isolated from pigs with clinical diseases and were generously donated by Nanjing Agricultural University and Jilin Agricultural University (28), respectively. Aerococcus urinae (A. urinae) ATCC 51268 was obtained from the American Type Culture Collection (ATCC). All the strains were cultured at $37^{\circ} \mathrm{C}$ on TSA (trypticase soy agar, Sigma, Shanghai, China) containing $5 \%$ defibrinated sheep blood. Subsequently, the bacteria were cultured routinely at $37^{\circ} \mathrm{C}$ in brain-heart infusion (BHI, BectonDickinson, Franklin Lakes, NJ, USA) broth and stored in $30 \%$ glycerol at $80^{\circ} \mathrm{C}$.

\section{Stability of Phage vB_AviM_AVP at Different pH Values and Temperatures}

The bacteriophage AVP was isolated by co-cultivation of host bacteria and sewage samples in BHI medium as reported previously (26), previous studies have shown that AVP has a latent phase of $15 \mathrm{~min}$ and a burst size of $139 \mathrm{PFU} / \mathrm{cell}$, and its optimal multiplicity of infection is 0.001 (Figure S2). To determine whether AVP has potential as a therapeutic phage, further stability determination is necessary.

To determine the $\mathrm{pH}$ stability of the phage, the titres were determined by the double-layer agar method after incubating the same concentration of phage suspensions in SM buffer ( $\mathrm{pH}: 1-12)$ at $37^{\circ} \mathrm{C}$ for $2 \mathrm{~h}$. For the detection of bacteriophage temperature stability, $10^{8} \mathrm{PFU}$ (plaque forming unit) of bacteriophage suspensions were incubated at $25^{\circ} \mathrm{C}, 40^{\circ} \mathrm{C}, 50^{\circ} \mathrm{C}, 60^{\circ} \mathrm{C}$, and $70^{\circ} \mathrm{C}$ for $100 \mathrm{~min}$, and samples were taken at 20 -min intervals for titer determination.

\section{Determination of Host Range of Phage AVP}

In this experiment, a total of 14 strains of $A$. viridans and 1 strain of $A$. urinae were used to detect the host range of phage AVP. CsCl density gradient centrifugation was used for phage purification, as previously described (26). Ten microlitres of purified phage AVP was dropped onto plates that were covered with bacterial lawns of different Aerococci strains. The host range was characterized by spot test and assayed at $37^{\circ} \mathrm{C}$ for $18-24 \mathrm{~h}$. 


\section{A. viridans-Induced Murine Mastitis Model}

Specific-pathogen-free 6-8-week-old female BALB/c pregnant mice (18-20 d old) were purchased from the Experimental Animal Center of Jilin University. During the experiment, the mice were kept in the animal room with a temperature-controlled and light-dark (light: 8:00-20:00) cycle. Feed and fresh water were available ad libitum.

The murine mastitis model was established according to a previous description with minor modifications (29). Briefly, female mice at 7-10 days of lactation were used for mammary gland inoculation, and the pups were separated from lactating mice $1-2 \mathrm{~h}$ before the experiment. A mixture of ketamine (87 $\mathrm{mg} / \mathrm{kg}$ ) and xylazine $(13 \mathrm{mg} / \mathrm{kg})$ was used for intraperitoneal anesthesia in mice before challenge (29).

\section{Bacteriophage Therapy in a Murine Mastitis Model}

In this study, a total of 36 lactating $\mathrm{BALB} / \mathrm{c}$ mice were randomized into 6 groups: (1) Bacteria-PBS group; (2) BacteriaAVP-L group; (3) Bacteria-AVP-M group; (4) Bacteria-AVP-H group; (5) Control group; and (6) Safety-Control group. The teat tips of the fourth pair of mammary glands were cut off, and 50 $\mu \mathrm{L}$ of $A$. viridans $\mathrm{N} 14$ suspension $\left(5 \times 10^{6} \mathrm{CFU} /\right.$ gland $)$ was delivered into both the left and right mammary glands of 4 groups of mice through the exposed teat canal with a 32-gauge blunted needle. The other 2 groups were the Control group (50 $\mu \mathrm{L}$ sterile $\mathrm{PBS} /$ gland) and the Safety-Control group only with $50 \mu \mathrm{L}$ phage $\operatorname{AVP}\left(5 \times 10^{7} \mathrm{PFU} /\right.$ gland $)$ intramammary injection.

To determine the effect of phage AVP against murine mastitis, $4 \mathrm{~h}$ after $A$. viridans challenge, the above 4 groups of infected mice were intramammarily inoculated with $50 \mu \mathrm{L}$ of sterile PBS (Bacteria-PBS group), low dose $\left(5 \times 10^{5} \mathrm{PFU} /\right.$ gland, BacteriaAVP-L group), medium dose $\left(5 \times 10^{6} \mathrm{PFU} /\right.$ gland, BacteriaAVP-M group), and high dose $\left(5 \times 10^{7} \mathrm{PFU} /\right.$ gland, BacteriaAVP-H group) of purified phage AVP. The other two groups of mice were not treated. All mice were euthanized by cervical dislocation $24 \mathrm{~h}$ after challenge, and the mammary glands were aseptically removed. One portion of weighed mammary glands was resuspended in sterile PBS, and sterile mortars and motordriven Teflon pestles (JinTai, Changchun, China) were further used for homogenization. To determine the bacterial load in the mammary glands, $100 \mu \mathrm{L}$ of serially diluted homogenates were counted on BHI agar plates. The PFU of all phagetreated groups was obtained by centrifuging the mammary gland homogenate at $4^{\circ} \mathrm{C}$ for $5 \mathrm{~min}(12,000 \times \mathrm{g})$ and filtering and counting with $100 \mu \mathrm{L}$ of serially diluted filtrate on double-layer agar plates. The limits of detection (LOD) were CFU or PFU that could not be detected by directly counting the original homogenate. The other portion of the mammary glands was used for histopathological analysis, as well as the detection of MPO and inflammatory cytokines.

\section{Histological Evaluation of Breast Tissues}

Histopathological analysis of mammary gland tissues of different treatment groups was performed. Briefly, all mice were euthanized at $24 \mathrm{~h}$ post-inoculation, and mammary glands were removed. Tissue samples from mammary glands were immediately fixed in $4 \%$ paraformaldehyde and further embedded in paraffin and sectioned. In addition, pathological damage to the breast tissue was evaluated by haematoxylin and eosin (H\&E) staining with optical microscopy.

\section{MPO (Myeloperoxidase) Activity Detection and Inflammatory Cytokine Assay}

MPO is a functional and activation marker of neutrophils (30), and its activity was detected as follows. Briefly, aseptically collected mammary tissues were weighed and added to HEPES (containing $0.1 \mathrm{mg} / \mathrm{mL}$ of STI) buffer solution at $0.2 \mathrm{~g} / \mathrm{mL}$. After grinding $(50 \mathrm{~Hz}, 10 \mathrm{~s}$ interval) for $20 \mathrm{~min}$, the homogenate was centrifuged at $4{ }^{\circ} \mathrm{C}$ for $30 \mathrm{~min}$ at $12,000 \times \mathrm{g}$. Next, an equal volume of $0.5 \%$ CTAC was added to the precipitate, which was ground and centrifuged again. Finally, the collected 5-fold diluted supernatants were measured for changes in absorbance at $450 \mathrm{~nm}$ using a 96-well plate reader to evaluate activity.

Enzyme-linked immunosorbent assay (ELISA) kits for detecting TNF- $\alpha$, IL- $1 \beta$, and IL- 6 in the mammary glands were obtained from Biolegend (San Diego, CA, USA), and the operation was performed according to the manufacturer's instructions. In brief, breast tissues were ground $(50 \mathrm{~Hz}$, $10 \mathrm{~s}$ interval) for $20 \mathrm{~min}$ after adding sterile PBS buffer at $0.2 \mathrm{~g} / \mathrm{mL}$. After centrifugation at $4^{\circ} \mathrm{C}$ for $20 \mathrm{~min}$ at $12,000 \times \mathrm{g}$, the supernatant was used for the detection of inflammatory cytokines.

\section{Statistical Analysis}

All statistical analyses were performed using SPSS version 13.0 software (SPSS, Inc., Chicago, IL, USA). The significance of experimental data in vivo was determined with a nonparametric Kruskal-Wallis test followed by pairwise comparisons. ${ }^{*} P<$ 0.05 , ${ }^{* *} P<0.01$, and ${ }^{* * *} P<0.001$ were considered to indicate significance. The error bars represent the standard deviation (SD) of the mean.

\section{RESULTS}

\section{Isolation and Identification of $\boldsymbol{A}$. viridans}

The strains isolated from clinical mastitis samples can form typical alpha haemolysis after culture on blood agar plates, and the paired or clustered Gram-positive cocci were observed under the microscope. The $16 \mathrm{~S}$ rRNA gene fragments of A. viridans strains were amplified using PCR, and the fragments measured $\sim 540$ bp according to gel electrophoresis (Figure S1) and sequencing. Nucleotide-Blast analysis of sequencing results showed that they have $97-100 \%$ identity with A. viridans in the GenBank database.

\section{pH and Thermal Stability}

As shown in Figure 1A, phage AVP showed pH stability. There was no change in the phage titer after a 2-h incubation in SM buffer ( $\mathrm{pH} 3-11)$. However, the phage activity was completely lost when the $\mathrm{pH}$ was lower than 3 or higher than 11 . The phage activity at different temperatures is shown in Figure 1B. When the temperature was $25^{\circ} \mathrm{C}, 40^{\circ} \mathrm{C}$, and $50^{\circ} \mathrm{C}$, the phage titer 

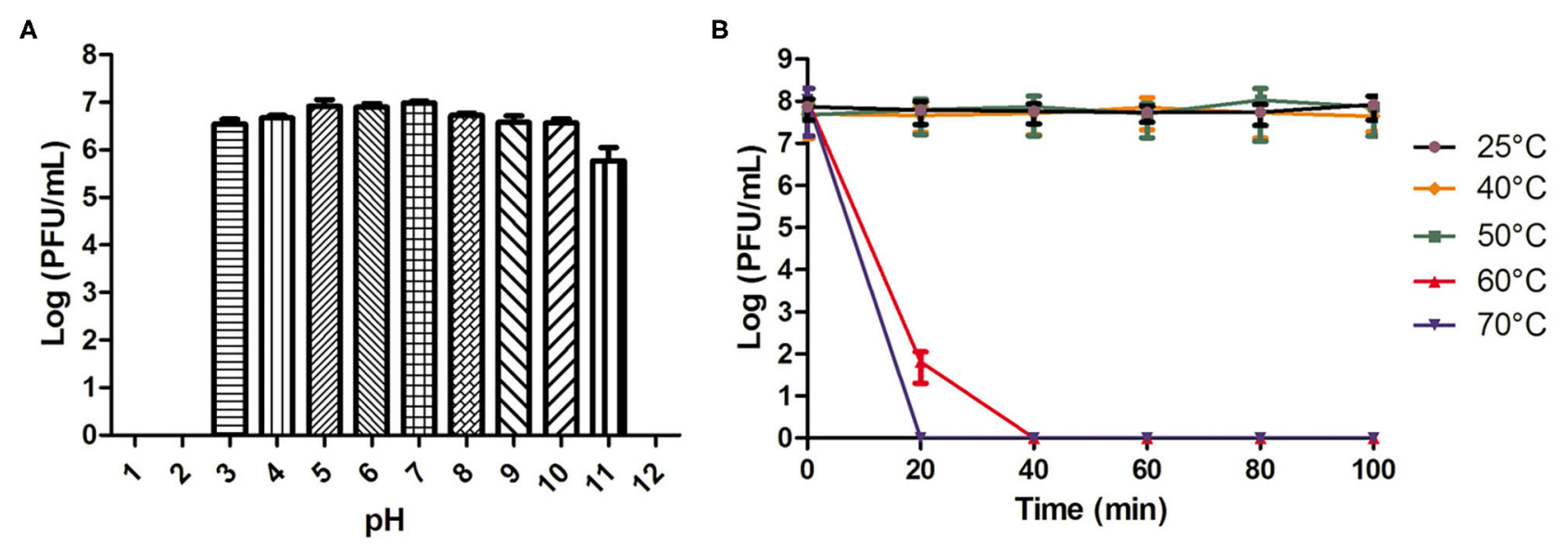

FIGURE 1 | pH and temperature stability of phage AVP. (A) The stability of phage AVP in SM buffer at different pH values for $2 \mathrm{~h}$. (B) Stability of phage AVP performed at $25^{\circ} \mathrm{C}, 40^{\circ} \mathrm{C}, 50^{\circ} \mathrm{C}, 60^{\circ} \mathrm{C}$, and $70^{\circ} \mathrm{C}$ during $100 \mathrm{~min}$. The Y-axis shows the log of plaque-forming units per milliliter (PFU/mL). Each assay was performed in triplicate, and the values represented are the means \pm SD. N.D. not detected.

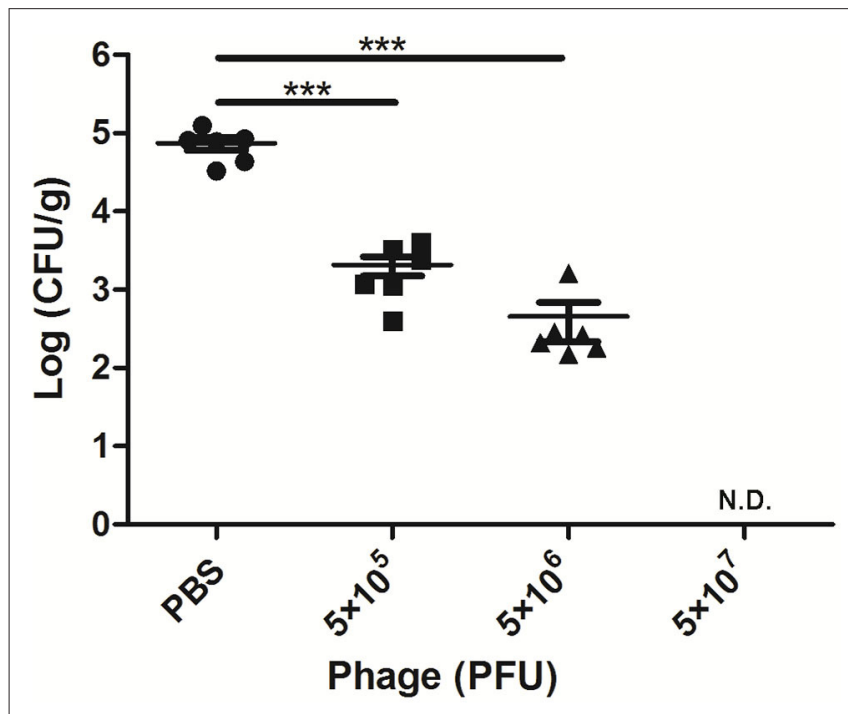

FIGURE 2 | Bacterial load in the mammary glands of mice. The bacterial load in the mammary glands of mice in different treatment groups after $24 \mathrm{~h}$ of A. viridans challenge was detected. The mice infected with $5 \times 10^{6} \mathrm{CFU}$ of A. viridans $\mathrm{N} 14$ were treated with different doses of phage or PBS. At $24 \mathrm{~h}$ post-infection, ten-fold serially diluted mammary gland homogenates were plated to count bacterial CFU. Each icon on the figure corresponds to an individual gland. All data are shown as the mean \pm SD. N.D. not detected. ${ }^{\star} P<0.05,{ }^{\star \star} P<0.01,{ }^{\star \star \star} P<0.001$ compared to PBS treated group.

showed no drop within $100 \mathrm{~min}$. However, at $60^{\circ} \mathrm{C}$ and $70^{\circ} \mathrm{C}$, the phage completely lost its activity at 40 and $20 \mathrm{~min}$, respectively.

\section{Host Range of Phage AVP}

As shown in Table S1, of all 15 strains tested, in addition to the host strain AV-X1 (isolated from pigs), AVP can also lyse 3 strains of $A$. viridan isolated from pigs and 4 strains of $A$. viridan

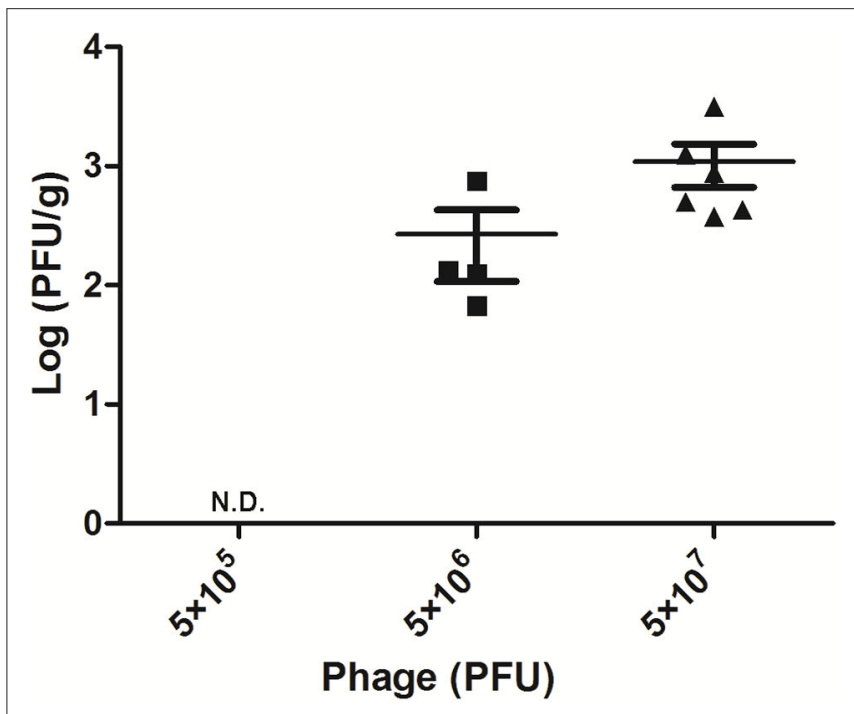

FIGURE 3 | Mammary gland PFU post phage treatment. The phage counts of all the Bacteria-AVP groups were observed in mammary glands. The mammary glands of mice with different doses of phage treatment were homogenized and filtered at $24 \mathrm{~h}$ post-infection. The double-layer agar plate method was used to detect PFU in the mammary gland. Each icon on the figure corresponds to an individual gland. All data are shown as the mean \pm SD.

isolated from bovines. However, AVP has no lytic activity against A. urinae ATCC 51268.

\section{Phage AVP Reduces Bacterial Load in Mammary Glands}

After $24 \mathrm{~h}$ of $A$. viridans challenge, a bacterial load of nearly $7.4 \times 10^{4} \mathrm{CFU} / \mathrm{g}$ was detected in the mammary glands of the infected mice treated with PBS (Figure 2). When the mice were treated with AVP $4 \mathrm{~h}$ after challenge, the number of colonies in 

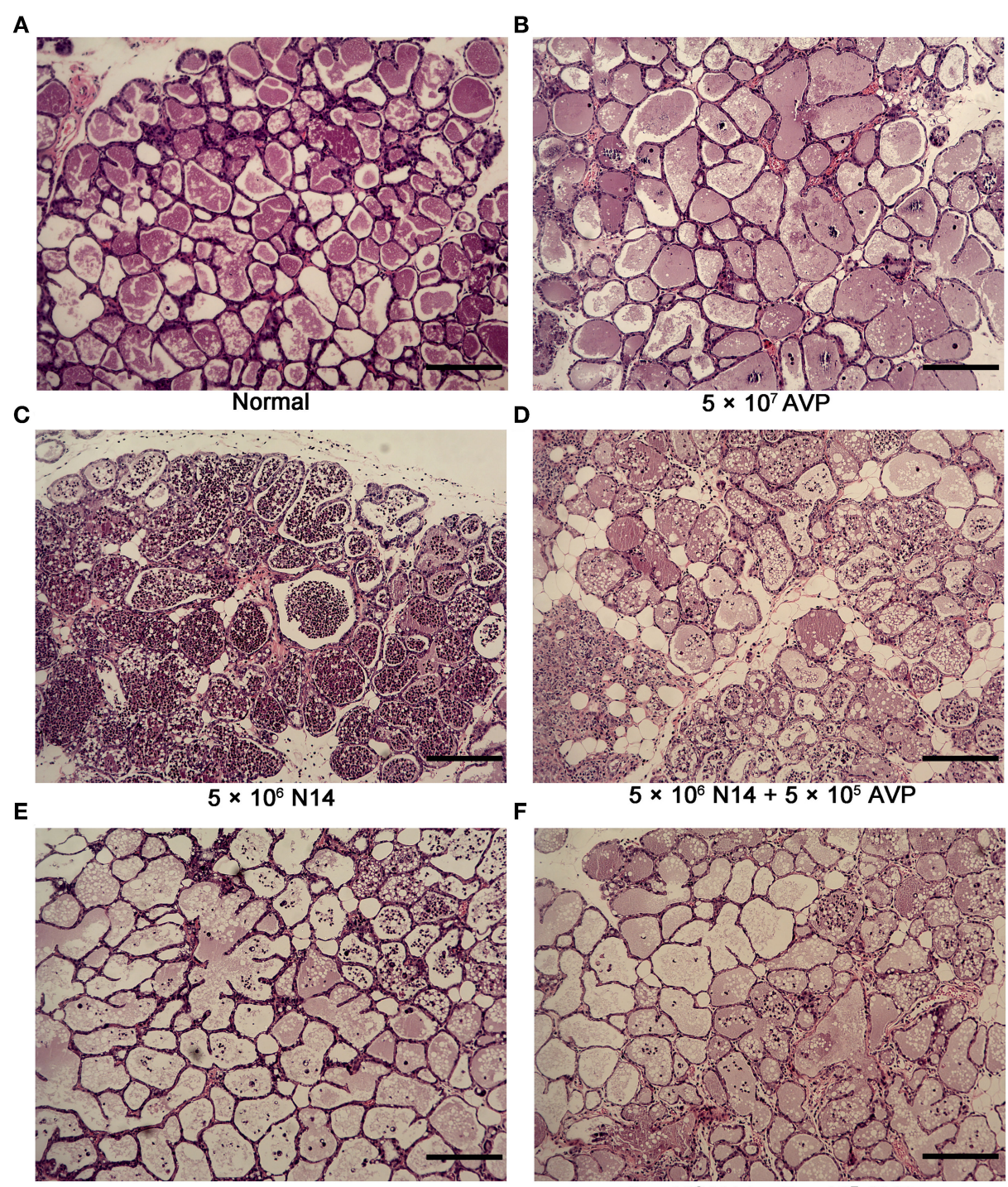

$\mathbf{F}$

$5 \times 10^{6} \mathrm{~N} 14+5 \times 10^{6}$ AVP

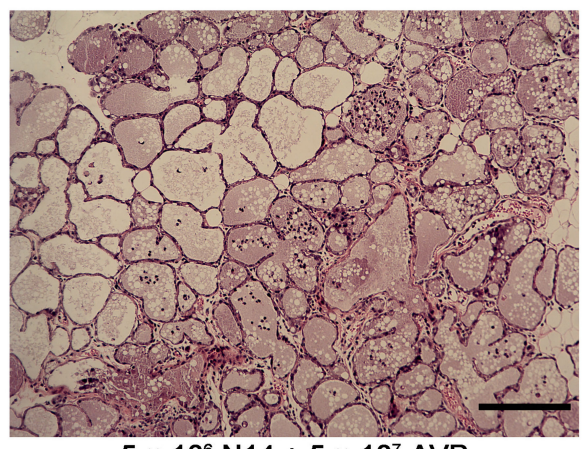

$5 \times 10^{6} \mathrm{~N} 14+5 \times 10^{7} \mathrm{AVP}$

FIGURE 4 | Histopathological examination of murine mammary glands. At $24 \mathrm{~h}$ post-inoculation of $A$. viridans N14 with or without AVP treatment, the mammary glands were removed for histopathological analysis. Representative H\&E-stained mammary tissues from each group are shown (100x). (A) The Control group

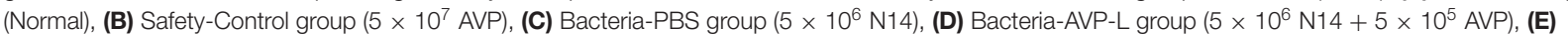
Bacteria-AVP-M group $\left(5 \times 10^{6} \mathrm{~N} 14+5 \times 10^{6}\right.$ AVP), (F) Bacteria-AVP-H group $\left(5 \times 10^{6} \mathrm{~N} 14+5 \times 10^{7}\right.$ AVP). Scale bar $=200 \mu \mathrm{m}$.

the mammary glands was significantly reduced $(P<0.001)$. The bacterial loads of the Bacteria-AVP-L group and Bacteria-AVP-M group were $2.1 \times 10^{3} \mathrm{CFU} / g$ and $4.5 \times 10^{2} \mathrm{CFU} / g$, respectively. In the high-dose phage-treated mice, no colonies were detected in the mammary glands.

\section{Titer of Phage AVP in Mammary Glands After Therapy}

To detect the phage titer in the mammary glands treated with different doses of AVP $24 \mathrm{~h}$ after challenge, the double-layer plate method was used to count phage in their tissue homogenates. No phage was detected in the Bacteria-AVP-L group. In contrast, phage remained in the mammary glands of the Bacteria-AVP-M group $\left(1.8 \times 10^{2} \mathrm{PFU} / \mathrm{g}\right)$ and the Bacteria-AVP-H group $(8.7 \times$ $10^{2} \mathrm{PFU} / \mathrm{g}$ ) after $24 \mathrm{~h}$ (Figure 3 ).

\section{Effects of Phage AVP on A. viridans-Induced Mastitis Histopathological Changes}

To investigate the protective effect of phage AVP on A. viridansinduced mastitis in mice, $\mathrm{H} \& \mathrm{E}$ staining was used to analyse the pathological changes of the mammary glands (Figures 4A-F). Histopathological analysis showed that the control group had intact acinar walls and no inflammatory cell infiltration, showing the normal structure of breast cells (Figure 4A). In contrast, the 
acinar integrity of the Bacteria-PBS group was destroyed, and the acinar wall was thickened, which was accompanied by a large amount of inflammatory cell infiltration (Figure 4C). After phage therapy, the damage to the acinar structure caused by $A$. viridans was considerably weaker than that of the Bacteria-PBS group, and neutrophil infiltration was alleviated (Figures 4D-F). However, intact structure and no typical pathological damage were found in the Safety-Control group, indicating the safety of phage AVP application in this study.

\section{Effects of Phage AVP on MPO Activity and Inflammatory Cytokines in a Murine Mastitis Model}

The inflammation level was assessed indirectly based on the level of the neutrophil marker MPO. After A. viridans infection, the accumulation of neutrophils in the mammary glands of the Bacteria-PBS group was significantly elevated (Figure 5). In contrast, MPO activity significantly decreased and approached the level of the control group after medium- and high-dose phage treatment (Figure 5, $P<0.001$ ). Furthermore, there was no significant difference between the Control group and the SafetyControl group, which corresponded to the pathological changes.

Inflammatory cytokines in the breast were also measured. As shown in Figure 6, the levels of TNF- $\alpha$, IL-1 $\beta$, and IL-6 after phage treatment were significantly lower than those of the Bacteria-PBS group $(P<0.001)$. In particular, the levels of IL-1 $\beta$ and IL- 6 in the medium-dose and high-dose phagetreated groups were close to those in the control group. Similarly, the Safety-Control group did not show a significant increase in inflammatory cytokine levels compared to the Control group.

\section{DISCUSSION}

The main bacteria causing mastitis in dairy cows are Streptococcus dysgalactiae, Streptococcus uberis, S. agalactiae, S. aureus, and E. coli $(31,32)$; the latter three have been identified and studied by animal models (33-35). In particular, some studies have used phages to treat a mouse mastitis model caused by $S$. aureus and $E$. coli, which have shown therapeutic effects in vivo $(25,36,37)$, indicating that the application of phages is safe and effective. Although the currently reported efficacy of bacteriophages on mastitis cows is absent or highly limited with a curation rate of only $16.7 \%(38,39)$, which may indicate that more research is needed to investigate the complex interactions of phages and bacteria in vivo.

Bovine mastitis caused by A. viridans could not be overlooked. It is easy to mistake this bacterium for Staphylococcus or Streptococcus $(40,41)$, resulting in misjudgment and mistreatment. Misidentifying the bacteria will also have a strongly negative effect for phage therapy against $A$. viridans, considering phage species specificity. In fact, the mastitis caused by $A$. viridans is more serious than previously known. Additionally, with the long-term and large-scale use of antibiotics in the dairy industry, the problem of antibiotic resistance has become increasingly serious. The same problem is observed in the case of $A$. viridans, which has developed resistance to most

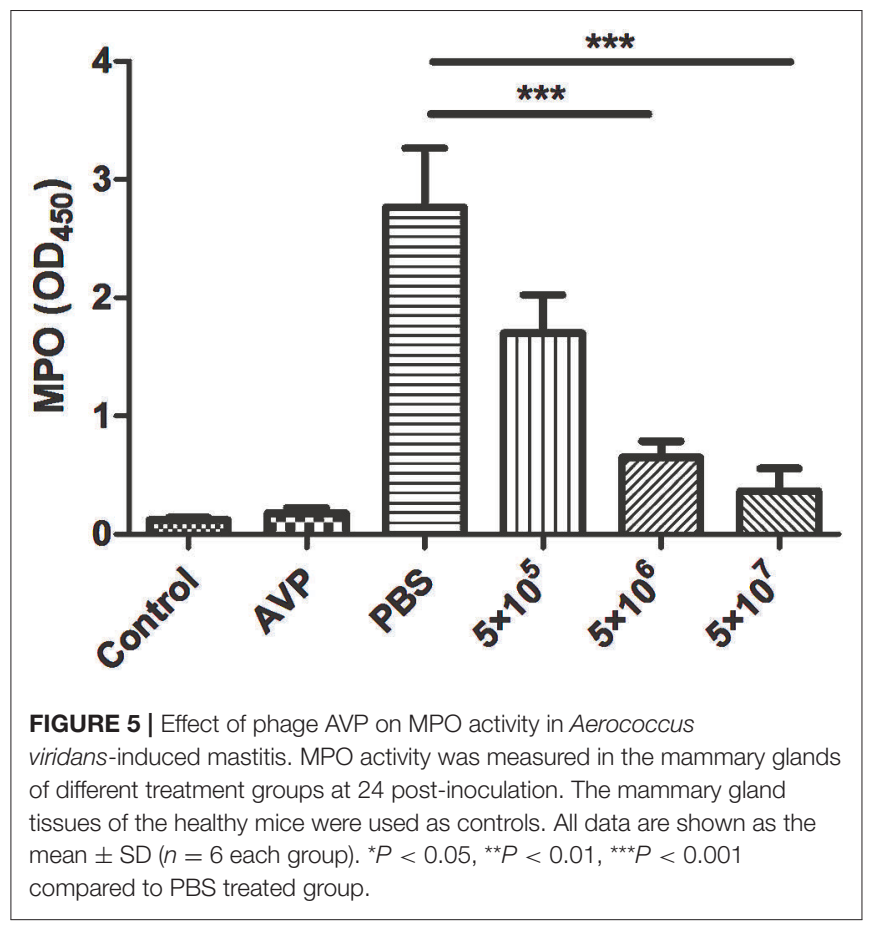

of the commonly used antibiotics usually used for Gram-positive bacteria $(14,42,43)$. There have been reports that $A$. viridans is even resistant to vancomycin and other back-up antibiotics $(17,44)$. Therefore, the use of antibiotics for the infection of potentially drug-resistant $A$. viridans will be limited. In addition, the application of antibiotics will cause the residue of antibiotics to exist in milk in a certain period of time, which will bring further losses to farmers and other unknown health risks to milk consumers. In contrast, phages are specific against certain strains of bacteria, and there are no reports about their harmful effects on both humans and animals (45).

In this work, we used a murine model of $A$. viridans induced mastitis, which showed typical symptoms of bovine mastitis as reported before (29). To date, AVP isolated in our earlier stage is the only reported bacteriophage that infects $A$. viridans. To verify the potential of its therapeutic value, we used AVP to treat the mastitis model. Our results showed that AVP can effectively remove $A$. viridans in the murine mastitis model, and the bactericidal effect of the phage is not affected by other factors in vivo. Comprehensive evaluation of pathological tissue sections, MPO activity, and inflammatory factor levels showed that phage treatment significantly improved the inflammation of breast tissue. These results are similar to the reported therapeutic effect of phage therapy on murine mastitis caused by other bacteria $(25,37)$, which further indicates the effectiveness of phage therapy in the treatment of mastitis.

This experiment is a therapeutic study of bacteriophages in mice infected with $A$. viridans. It is necessary to conduct research on the preventive effect of bacteriophages on mastitis. In future work, more strains, different times of phage administration and long-term follow-up will be involved to conduct in-depth 
A

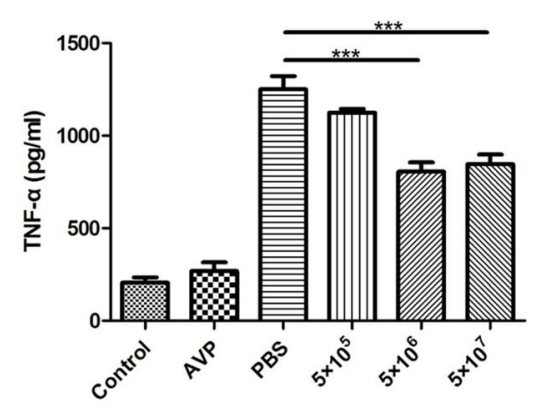

B

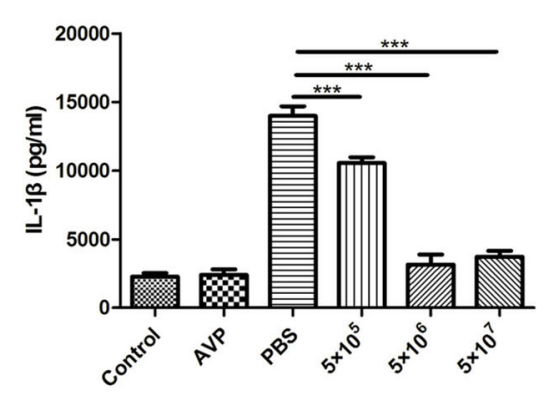

C

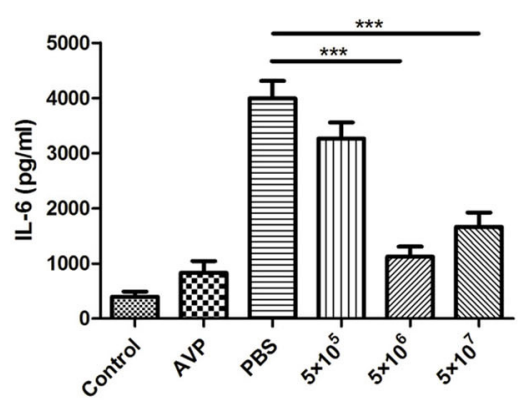

FIGURE 6 | Cytokine levels in the mammary gland. At $24 \mathrm{~h}$ post-inoculation, the levels of pro-inflammatory cytokines in all mammary glands were measured with an enzyme-linked immunosorbent assay. The levels of TNF- $\alpha$ (A), IL-1 $\beta$ (B), and IL-6 (C) in murine mammary gland tissue of all treatment groups were determined. The tissues of the healthy mice served as controls. All data are shown as the mean $\pm \mathrm{SD}\left(n=6\right.$ each group). ${ }^{\star} P<0.05$, ${ }^{\star \star} P<0.01,{ }^{\star \star \star} P<0.001$ compared to PBS treated group.

research on the efficacy of phages; in particular, bona fide studies in dairy cattle are necessary. In addition, the residual $A$. viridans in faces, bedding materials and utensils are also responsible for bovine infection (15). It is conceivable that the bacteriophage AVP can be used as a spray to disinfect the farm environment and thus reduce infections by A. viridans, and AVP could play this effective preventive role based on its stability at different $\mathrm{pHs}$ and temperatures.

It must be acknowledged that phages are highly specific, which is an advantage and a limitation. Therefore, the selection of appropriate phages is the key factor for prophylactic or therapeutic applications. Because phage therapy belongs to precise and personalized therapy, it is necessary to specifically select appropriate phages for the prevention and treatment of a specific farm or patient. On the other hand, phages still exist in the mammary gland $24 \mathrm{~h}$ post-inoculation in this experiment, which is conducive to the further elimination of residual bacteria. Longer observation periods may enable further reduction of colonies and improvement of inflammation; nevertheless, the risk of bacterial resistance is also increased. However, both of the above disadvantages can be compensated for by phage cocktail therapy (46). In addition, mastitis in the clinic is likely to be caused by the coinfection of multiple bacteria; therefore, phages of various bacteria may need to be combined into a cocktail to achieve better prevention and treatment effects. Overall, phage use is indeed safe and promising, but there are a number of challenges that remain to be addressed.

\section{CONCLUSIONS}

In this study, the murine mastitis model was established by using A. viridans. A. viridans infection caused significant pathological damage to the mammary gland tissue of mice. AVP can effectively eliminate the $A$. viridans that causes mastitis in mice. In addition, the application of AVP can effectively ameliorate the pathological damage to the mammary gland caused by $A$. viridans infection and the subsequent development of inflammation, as indicated by the histological analysis of mammary gland tissue and the measurement of MPO activities and pro-inflammatory cytokines. In summary, AVP has shown pharmaceutical potential in the treatment of mastitis caused by $A$. viridans. The results of this study indicate that bacteriophages are promising candidates for controlling bacterial infection.

\section{DATA AVAILABILITY STATEMENT}

All datasets presented in this study are included in the article/Supplementary Material.

\section{ETHICS STATEMENT}

The animal study was reviewed and approved by Animal Welfare and Research Ethics Committee at Jilin University.

\section{AUTHOR CONTRIBUTIONS}

WH and JG contributed to conception and design of the study. HX, DH, DL, GW, YJ, and LY performed the experiments. HX and DL wrote the first draft of the manuscript. SL, GW, YJ, XW, ZW, LB, RZ, HZ, LY, and ZG conducted data collection, statistical analysis, and wrote sections of the manuscript. $\mathrm{DH}, \mathrm{DL}, \mathrm{RZ}, \mathrm{HZ}, \mathrm{LB}$, and JG contributed to manuscript revision. All authors read and approved the submitted version. All authors contributed to the article and approved the submitted version.

\section{FUNDING}

This work was financially supported through grants from the National Natural Science Foundation of China (No. 31872505 and U19A2038), the Natural Science Foundation of Jilin Province (Changchun, China; grant no. 20200201120JC), the Jilin Province Science Foundation for Youths (Changchun, China; grant no. 20190103106JH), the Fundamental Research 
Funds for the Central Universities and the Achievement Transformation Project of the First Hospital of Jilin University (No. JDYYZH-1902025).

\section{ACKNOWLEDGMENTS}

We would like to give our special thanks to Dr. Yunhang Gao from Jilin Agricultural University and Dr. Zihao Pan

\section{REFERENCES}

1. Kumar N, Manimaran A, Kumaresan A, Jeyakumar S, Sreela L, Mooventhan $\mathrm{P}$, et al. Mastitis effects on reproductive performance in dairy cattle: a review. Trop Anim Health Prod. (2017) 49:663-73. doi: 10.1007/s11250-017-1253-4

2. Gomes F, Henriques M. Control of Bovine Mastitis: Old and Recent Therapeutic Approaches. Curr Microbiol. (2016) 72:377-82. doi: 10.1007/s00284-015-0958-8

3. Manyi-Loh C, Mamphweli S, Meyer E, Okoh A. Antibiotic Use in Agriculture and Its Consequential Resistance in Environmental Sources: Potential Public Health Implications. Molecules. (2018) 23:4. doi: 10.3390/molecules23040795

4. Founou LL, Founou RC, Essack SY. Antibiotic Resistance in the Food Chain: A Developing Country-Perspective. Front Microbiol. (2016) 7:1881. doi: $10.3389 /$ fmicb. 2016.01881

5. Infectious Diseases Society of, Spellberg B, Blaser M, Guidos RJ, Boucher HW, Bradley JS, et al. Combating antimicrobial resistance: policy recommendations to save lives. Clin Infect Dis. (2011) 52 Suppl 5:S397-428. doi: 10.1093/cid/cir153

6. Olde Riekerink RG, Barkema HW, Veenstra S, Poole DE, Dingwell RT, Keefe GP. Prevalence of contagious mastitis pathogens in bulk tank milk in Prince Edward Island. Can Vet J. (2006) 47:567-72. doi: 10.1080/03079450600717349

7. Pitkala A, Haveri M, Pyorala S, Myllys V, Honkanen-Buzalski T. Bovine mastitis in Finland 2001-prevalence, distribution of bacteria, antimicrobial resistance. J Dairy Sci. (2004) 87:243341. doi: 10.3168/jds.S0022-0302(04)73366-4

8. Schukken YH, Gonzalez RN, Tikofsky LL, Schulte HF, Santisteban CG, Welcome FL, et al. CNS mastitis: nothing to worry about? Vet Microbiol. (2009) 134:9-14. doi: 10.1016/j.vetmic.2008.09.014

9. Heikkila AM, Liski E, Pyorala S, Taponen S. Pathogen-specific production losses in bovine mastitis. J Dairy Sci. (2018) 101:9493504. doi: 10.3168/jds.2018-14824

10. Sun M, Gao J, Ali T, Yu D, Zhang S, Khan SU, et al. Characteristics of Aerococcus viridans isolated from bovine subclinical mastitis and its effect on milk SCC, yield, and composition. Trop Anim Health Prod. (2017) 49:8439. doi: 10.1007/s11250-017-1271-2

11. Spakova T, Elecko J, Vasil M, Legath J, Pristas P, Javorsky P. Limited genetic diversity of Aerococcus viridans strains isolated from clinical and subclinical cases of bovine mastitis in Slovakia. Pol J Vet Sci. (2012) 15:3295. doi: 10.2478/v10181-012-0051-1

12. Williams RE, Hirch A, Cowan ST. Aerococcus, a new bacterial genus. J Gen Microbiol. (1953) 8:475-80. doi: 10.1099/00221287-8-3-475

13. Zadoks RN, Gonzalez RN, Boor KJ, Schukken YH. Mastitis-causing streptococci are important contributors to bacterial counts in raw bulk tank milk. J Food Prot. (2004) 67:2644-50. doi: 10.4315/0362-028X-67.12.2644

14. Liu G, Liu Y, Ali T, Ferreri M, Gao J, Chen W, et al. Molecular and Phenotypic Characterization of Aerococcus viridans Associated with Subclinical Bovine Mastitis. PLoS One. (2015) 10:e0125001. doi: 10.1371/journal.pone.0125001

15. Saishu N, Morimoto K, Yamasato H, Ozaki H, Murase T. Characterization of Aerococcus viridans isolated from milk samples from cows with mastitis and manure samples. J Vet Med Sci. (2015) 77:1037-42. doi: 10.1292/jvms.15-0100

16. Liu G, Yin J, Han B, Barkema HW, Shahid M, De Buck J, et al. Adherent/invasive capacities of bovine-associated Aerococcus viridans contribute to pathogenesis of acute mastitis in a murine model. Vet Microbiol. (2019) 230:202-11. doi: 10.1016/j.vetmic.2019.02.016 from Nanjing Agricultural University for generously providing A. viridans strains Aer- $1 \sim$ Aer- 6 and CZ4b-3, respectively.

\section{SUPPLEMENTARY MATERIAL}

The Supplementary Material for this article can be found online at: https://www.frontiersin.org/articles/10.3389/fvets. 2020.00588/full\#supplementary-material

17. Ahn K, Hwang GY, Uh Y, Yoon KJ, Hyun S. Vancomycin Resistance due to vanA Gene Expression in an Aerococcus viridans Isolate: First Case in Korea. Ann Lab Med. (2017) 37:288-9. doi: 10.3343/alm.2017.37.3.288

18. Verbeken G, Pirnay JP, De Vos D, Jennes S, Zizi M, Lavigne R, et al. Optimizing the European regulatory framework for sustainable bacteriophage therapy in human medicine. Arch Immunol Ther Exp (Warsz). (2012) 60:16172. doi: 10.1007/s00005-012-0175-0

19. Cisek AA, Dabrowska I, Gregorczyk KP, Wyzewski Z. Phage Therapy in Bacterial Infections Treatment: One Hundred Years After the Discovery of Bacteriophages. Curr Microbiol. (2017) 74:277-83. doi: 10.1007/s00284-016-1166-x

20. Gigante A, Atterbury RJ. Veterinary use of bacteriophage therapy in intensively-reared livestock. Virol J. (2019) 16:155. doi: 10.1186/s12985-019-1260-3

21. Biswas B, Adhya S, Washart P, Paul B, Trostel AN, Powell B, et al. Bacteriophage therapy rescues mice bacteremic from a clinical isolate of vancomycin-resistant Enterococcus faecium. Infect Immun. (2002) 70:20410. doi: 10.1128/IAI.70.1.204-210.2002

22. Wang J, Hu B, Xu M, Yan Q, Liu S, Zhu X, et al. Therapeutic effectiveness of bacteriophages in the rescue of mice with extended spectrum betalactamase-producing Escherichia coli bacteremia. Int J Mol Med. (2006) 17:347-55. doi: 10.3892/ijmm.17.2.347

23. Chan BK, Turner PE, Kim S, Mojibian HR, Elefteriades JA, Narayan D. Phage treatment of an aortic graft infected with Pseudomonas aeruginosa. Evol Med Public Health. (2018) 2018:60-6. doi: 10.1093/emph/eoy005

24. Geng H, Zou W, Zhang M, Xu L, Liu F, Li X, et al. Evaluation of phage therapy in the treatment of Staphylococcus aureus-induced mastitis in mice. Folia Microbiol (Praha). (2020) 65:339-51. doi: 10.1007/s12223-019-00729-9

25. da Silva Duarte V, Dias RS, Kropinski AM, Campanaro S, Treu L, Siqueira C, et al. Genomic analysis and immune response in a murine mastitis model of vB_EcoM-UFV13, a potential biocontrol agent for use in dairy cows. Sci Rep. (2018) 8:6845. doi: 10.1038/s41598-018-24896-w

26. Xi H, Dai J, Tong Y, Cheng M, Zhao F, Fan H, et al. The Characteristics and Genome Analysis of vB_AviM_AVP, the First Phage Infecting Aerococcus viridans. Viruses. (2019) 11:2. doi: 10.3390/v11020104

27. Grant KA, Dickinson JH, Collins MD, Kroll RG. Rapid identification of Aerococcus viridans using the polymerase chain reaction and an oligonucleotide probe. FEMS Microbiol Lett. (1992) 74:63-9. doi: 10.1111/j.1574-6968.1992.tb05343.x

28. Pan Z, Ma Y, Ma J, Dong W, Yao H. Acute meningitis of piglets and mice caused by co-infected with Streptococcus suis and Aerococcus viridans. Microb Pathog. (2017) 106:60-4. doi: 10.1016/j.micpath.2016. 10.024

29. Pereyra EAL, Sacco SC, Dure A, Baravalle C, Renna MS, Andreotti CS, et al. Immune response of Staphylococcus aureus strains in a mouse mastitis model is linked to adaptive capacity and genotypic profiles. Vet Microbiol. (2017) 204:64-76. doi: 10.1016/j.vetmic.2017.04.009

30. Ahn J, Ambrosone CB, Kanetsky PA, Tian C, Lehman TA, Kropp S, et al. Polymorphisms in Genes Related to Oxidative Stress (CAT, MnSOD, MPO, and eNOS) and Acute Toxicities from Radiation Therapy following Lumpectomy for Breast Cancer. Clinical Cancer Research. (2006) 12:706370. doi: 10.1158/1078-0432.CCR-06-0039

31. Ruegg PL. A 100-Year Review: Mastitis detection, management, and prevention. J Dairy Sci. (2017) 100:10381-97. doi: 10.3168/jds.2017-13023 
32. Sordillo LM. Mammary Gland Immunobiology and Resistance to Mastitis. Vet Clin North Am Food Anim Pract. (2018) 34:507-23. doi: 10.1016/j.cvfa.2018.07.005

33. Chen Z, Zhou J, Wang X, Zhang Y, Lu X, Fan Y, et al. Screening candidate microR-15a- IRAK2 regulatory pairs for predicting the response to Staphylococcus aureus-induced mastitis in dairy cows. J Dairy Res. (2019) 86:425-31. doi: 10.1017/S0022029919000785

34. $\mathrm{Pu} \mathrm{J,} \mathrm{Li} \mathrm{R,} \mathrm{Zhang} \mathrm{C,} \mathrm{Chen} \mathrm{D,} \mathrm{Liao} \mathrm{X,} \mathrm{Zhu} \mathrm{Y,} \mathrm{et} \mathrm{al.} \mathrm{Expression}$ profiles of miRNAs from bovine mammary glands in response to Streptococcus agalactiae-induced mastitis. J Dairy Res. (2017) 84:3008. doi: 10.1017/S0022029917000437

35. Luoreng ZM, Wang XP, Mei CG, Zan LS. Expression profiling of peripheral blood miRNA using RNAseq technology in dairy cows with Escherichia coliinduced mastitis. Sci Rep. (2018) 8:12693. doi: 10.1038/s41598-018-30518-2

36. Iwano $\mathrm{H}$, Inoue $\mathrm{Y}$, Takasago $\mathrm{T}$, Kobayashi $\mathrm{H}$, Furusawa $\mathrm{T}$, Taniguchi $\mathrm{K}$, et al. Bacteriophage PhiSA012 Has a Broad Host Range against Staphylococcus aureus and Effective Lytic Capacity in a Mouse Mastitis Model. Biology (Basel). (2018) 7:8. doi: 10.3390/biology7010008

37. Breyne K, Honaker RW, Hobbs Z, Richter M, Zaczek M, Spangler T, et al. Efficacy and Safety of a Bovine-Associated Staphylococcus aureus Phage Cocktail in a Murine Model of Mastitis. Front Microbiol. (2017) 8:2348. doi: 10.3389/fmicb.2017.02348

38. Gill JJ, Pacan JC, Carson ME, Leslie KE, Griffiths MW, Sabour PM. Efficacy and pharmacokinetics of bacteriophage therapy in treatment of subclinical Staphylococcus aureus mastitis in lactating dairy cattle. Antimicrob Agents Chemother. (2006) 50:2912-8. doi: 10.1128/AAC.01630-05

39. Lerondelle C, Poutrel B. Bacteriophage treatment trials on staphylococcal udder infection in lactating cows. Ann Rech Vet. (1980) 11:421-6.

40. Kerbaugh MA, Evans JB. Aerococcus viridans in the hospital environment. Appl Microbiol. (1968) 16:519-23. doi: 10.1128/AEM.16.3.519-523.1968
41. McDonald WL, Fry BN, Deighton MA. Identification of Streptococcus spp. causing bovine mastitis by PCR-RFLP of $16 S-23$ S ribosomal DNA. Vet Microbiol. (2005) 111:241-6. doi: 10.1016/j.vetmic.2005.10.012

42. Chen LY, Yu WC, Huang SH, Lin ML, Chen TL, Fung CP, et al. Successful treatment of Aerococcus viridans endocarditis in a patient allergic to penicillin. J Microbiol Immunol Infect. (2012) 45:158-60. doi: 10.1016/j.jmii.2011.09.010

43. Zhou W, Nanci V, Jean A, Salehi AH, Altuwaijri F, Cecere R, et al. Aerococcus viridans native valve endocarditis. Can J Infect Dis Med Microbiol. (2013) 24:155-8. doi: 10.1155/2013/470413

44. Zhou WQ, Niu DM, Zhang ZZ, Ning MZ, Shen H, Zhang K. Vancomycin resistance due to VanA in an Aerococcus viridans isolate. Indian J Med Microbiol. (2014) 32:462-5. doi: 10.4103/0255-0857.142238

45. Doss J, Culbertson K, Hahn D, Camacho J, Barekzi N. A Review of Phage Therapy against Bacterial Pathogens of Aquatic and Terrestrial Organisms. Viruses. (2017) 9:3. doi: 10.3390/v9030050

46. Chan BK, Abedon ST, Loc-Carrillo C. Phage cocktails and the future of phage therapy. Future Microbiol. (2013) 8:769-83. doi: 10.2217/fmb.13.47

Conflict of Interest: The authors declare that the research was conducted in the absence of any commercial or financial relationships that could be construed as a potential conflict of interest.

Copyright (c) $2020 \mathrm{Xi}, \mathrm{He}, \mathrm{Li}$, Liu, Wang, Ji, Wang, Wang, Bi, Zhao, Zhang, Yang, Guo, Han and Gu. This is an open-access article distributed under the terms of the Creative Commons Attribution License (CC BY). The use, distribution or reproduction in other forums is permitted, provided the original author(s) and the copyright owner(s) are credited and that the original publication in this journal is cited, in accordance with accepted academic practice. No use, distribution or reproduction is permitted which does not comply with these terms. 